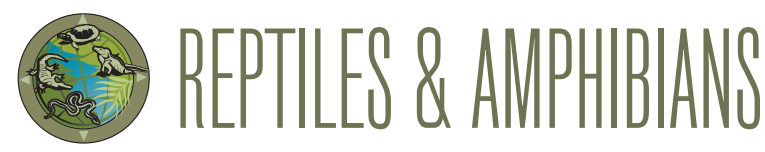

\title{
Ongoing Assessment of the Marsh Crocodile (Crocodylus palustris) Population in the Wetlands of Anand and Kheda Districts, Gujarat, India
}

\author{
Neel Talati ${ }^{1}$, Rita N. Kumar ${ }^{1}$, Dhara Tuteja ${ }^{1}$, and Nirmal Kumar ${ }^{2}$ \\ ${ }^{1}$ Department of Biological and Environmental Science, N. V. Patel College of Pure and Applied Sciences, Vallabh Vidyanagar-388120, Gujarat, India \\ (neel7007@gmail.com [corresponding author], rita@nvpas.edu.in, dharadesai0110@gmail.com) \\ ${ }^{2}$ P.G. Department of Environmental Science \& Technology (EST) Institute of Science \& Technology for Advanced Studies \& Research (ISTAR), \\ Vallabh Vidyanagar-388120, Gujarat, India (nirmalkumar@istar.edu.co.in)
}

$\mathrm{I}$ ndia has a variety of distinctive wetland habitats (Prasad et al. 2002), and Gujarat has the nation's highest percentage (22.8\%) of inland and coastal wetlands, comprising 201,503 wetlands plus an additional 555,557 such habitats with areas covering less than 2.25 ha (Ministry of Environment and Forests 2011). Inland wetlands include village ponds, lakes, reservoirs, streams, and canals, some of which are seasonal or temporary. Anand District in central Gujarat, which was carved out of Kheda District in 1997, has a total of 1,019 wetlands covering 67,570 ha; Kheda District has 1,243 mapped wetlands covering 14,415 ha.

Crocodilians are keystone species that play an important role in maintaining the complex webs of life in wetland environments (Whitaker 2007). As apex predators, they consume a wide variety of prey, and juveniles are prey of various preda- tors such as monitor lizards, turtles, birds, and even other crocodiles. Although humans and crocodiles have a long history of co-existence in India and, despite wide community awareness and warning signboards, crocodiles continue to pose a threat to people (e.g., Vyas 2010; Rao and Gurjwar 2013; Vasava et al. 2015a). However, humans are the greatest threat to crocodiles, populations of which are declining in many areas and are in need of protection (e.g., Vyas 2012).

Many wetlands in Anand $\left(22.5645^{\circ} \mathrm{N}, 72.9289^{\circ} \mathrm{E}\right)$ and Kheda $\left(22.7507^{\circ} \mathrm{N}, 72.6847^{\circ} \mathrm{E}\right)$ Districts harbor Marsh Crocodiles (Crocodylus palustris). We surveyed ponds for crocodiles in eight villages from Anand District (Deva, Petli, Changa, Malataj, Dabhou, Sojitra, Gada, and Dali) and six from Kheda District (Pij, Vaso, Heranj, Traj, Marala, Machhiel) (Fig. 1). Of the 14 villages surveyed, Deva had

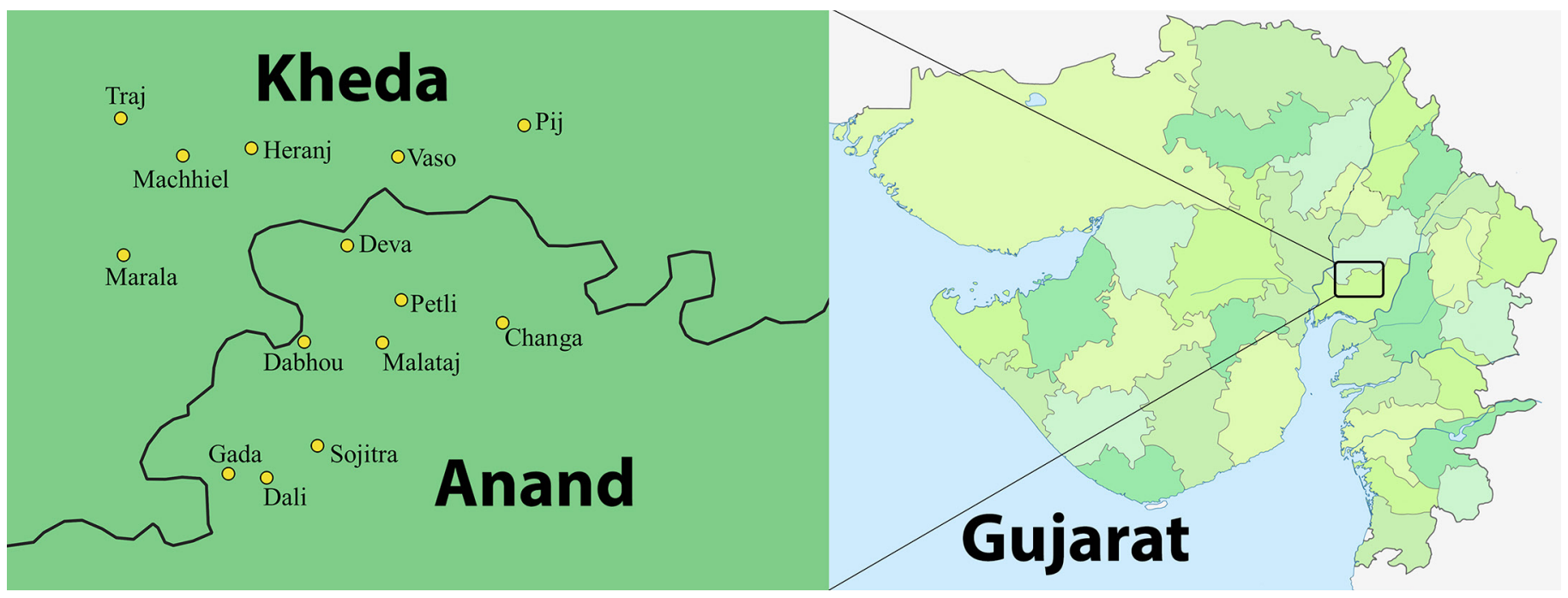

Fig. 1. Locations of ponds sampled for the presence of Marsh Crocodiles (Crocodylus palustris) in villages of Anand and Kheda Districts, Gujarat, India. 
three ponds, Heranj and Sojitra had two ponds each, and the remaining villages had a single pond. All provided water for irrigation and the majority also are leased by the government for fish farming.

We visited each site five times from December 2019 to February 2020. Winter is the best time to see crocodiles, which bask more frequently during the winter season (Downs et al. 2008). We used standard protocols (track surveys) (Fukuda et al. 2013 and references therein) from 0800 to $1600 \mathrm{~h}$ and supplemented our data by recording indirect evidence of crocodiles (e.g., pugmarks, tail marks, dens, or scat) in the area surrounding ponds.

We recorded a total of 220 crocodiles during the study period (Table 1; Fig. 2). The majority were basking on mounds, although smaller individuals and juveniles were basking in vegetation, presumably in order to hide from predators.

The ponds we sampled were included in annual citizenscience crocodile counts from 2013 to 2021 (Vasava et al. 2015b; Vasava 2016a, 2017, 2018, 2019, 2020, 2021) (the 2022 count was postponed due to concerns for the health of volunteers). Although their methods differed (5-12 volunteer observers, depending on the size of the wetland, counted crocodiles visible from assigned locations from $1000 \mathrm{~h}$ to $1400 \mathrm{~h}$ on a given day in January), we compared our results to those from the counts (Table 1). Despite some fluctuations from year to year, the count data suggest that the popula- tion of crocodiles in the region has been increasing. However, the fact that we encountered more crocodiles during our more extensive surveys than in any count indicates that multiple visits generated more accurate data than the short-term counts. So, although the counts are exceedingly valuable for identifying trends over time, we suggest that supplemental detailed surveys over an extended period are necessary for precise estimates of population sizes and that these be implemented at least at 2-3 year intervals to supplement the annual counts.

Regardless of the apparently increasing numbers of crocodiles in the region, many ponds support very few individuals and even the combined populations comprise a relatively small number of animals. That populations of crocodilians are small could be attributable to persecution by humans, lack of nesting sites, hatchling infertility, embryonic mortality, or predation (Menzies et al. 2014). Unfortunately, we lack the data to assess these risks at ponds in the study area. Also, crocodiles frequently migrate considerable distances during the breeding season from February to June (Whitaker and Whitaker 1984). All of the wetlands we sampled are interconnected by canals and high water levels during monsoons likely also facilitate relocations from one wetland to another. Again, we lack the necessary data to determine if crocodiles in any one pond are long-term residents or migrants from other wetlands. We recommend that future efforts to monitor the populations of Marsh Crocodiles in these wetlands incorporate means of

Table 1. Sampled villages with ponds in Anand and Kheda Districts, Gujarat, India, and numbers of Marsh Crocodiles (Crocodylus palustris) in the respective wetlands. Results of the present study are in bold; numbers from citizen-science crocodile counts in 2013-2021 are from Vasava et al. (2015b) and Vasava (2016, 2017, 2018, 2019, 2020, 2021).

\begin{tabular}{|c|c|c|c|c|c|c|c|c|c|c|c|}
\hline \multirow[b]{2}{*}{ District } & \multirow{2}{*}{\multicolumn{2}{|c|}{$\begin{array}{r}\text { Wetland } \\
\text { Area }\left(\mathrm{m}^{2}\right)\end{array}$}} & \multirow[b]{2}{*}{2013} & \multicolumn{8}{|c|}{ Number of Crocodiles } \\
\hline & & & & 2015 & 2016 & 2017 & 2018 & 2019 & 2019 & 2020 & 2021 \\
\hline Kheda & Heranj & $81,758,821$ & 14 & 9 & 9 & 20 & 8 & 7 & 34 & 23 & 27 \\
\hline Kheda & Marala & 614,302 & 9 & 13 & 2 & 10 & 10 & 7 & 8 & 7 & 3 \\
\hline Kheda & Traj & 389,796 & 10 & 8 & 12 & 9 & 4 & 13 & 20 & 6 & 24 \\
\hline Anand & Deva & 159,676 & 33 & 59 & 43 & 40 & 59 & 68 & 58 & 52 & 88 \\
\hline Anand & Dabhou & 92,231 & 2 & 2 & 0 & 2 & 4 & 12 & 24 & 13 & 8 \\
\hline Anand & Malataj & 66,859 & 10 & 15 & 14 & 19 & 10 & 16 & 25 & 21 & 21 \\
\hline Anand & Sojitra & 53,379 & 1 & 2 & 1 & 1 & 2 & 3 & 6 & 0 & 6 \\
\hline Kheda & $\mathrm{Pij}$ & 53,335 & 2 & 2 & 2 & 2 & 3 & 2 & 2 & 5 & 4 \\
\hline Kheda & Vaso & 52,368 & 6 & 6 & 4 & 8 & 7 & 8 & 15 & 10 & 9 \\
\hline Kheda & Machhiel & 43,717 & 2 & 1 & 1 & 1 & 0 & - & 2 & - & - \\
\hline Anand & Gada & 33,406 & 0 & 0 & 0 & 0 & 0 & 0 & 2 & 0 & 0 \\
\hline Anand & Dali & 31,820 & 0 & 0 & 0 & 0 & 0 & 0 & 1 & 0 & 1 \\
\hline Anand & Petli & 19,621 & 4 & 0 & 12 & 11 & 10 & 14 & 19 & 13 & 14 \\
\hline Anand & Changa & 19,385 & 1 & 1 & 4 & 3 & 3 & 2 & 4 & 1 & 1 \\
\hline Totals & & & 94 & 118 & 104 & 126 & 120 & 152 & 220 & 151 & 206 \\
\hline
\end{tabular}




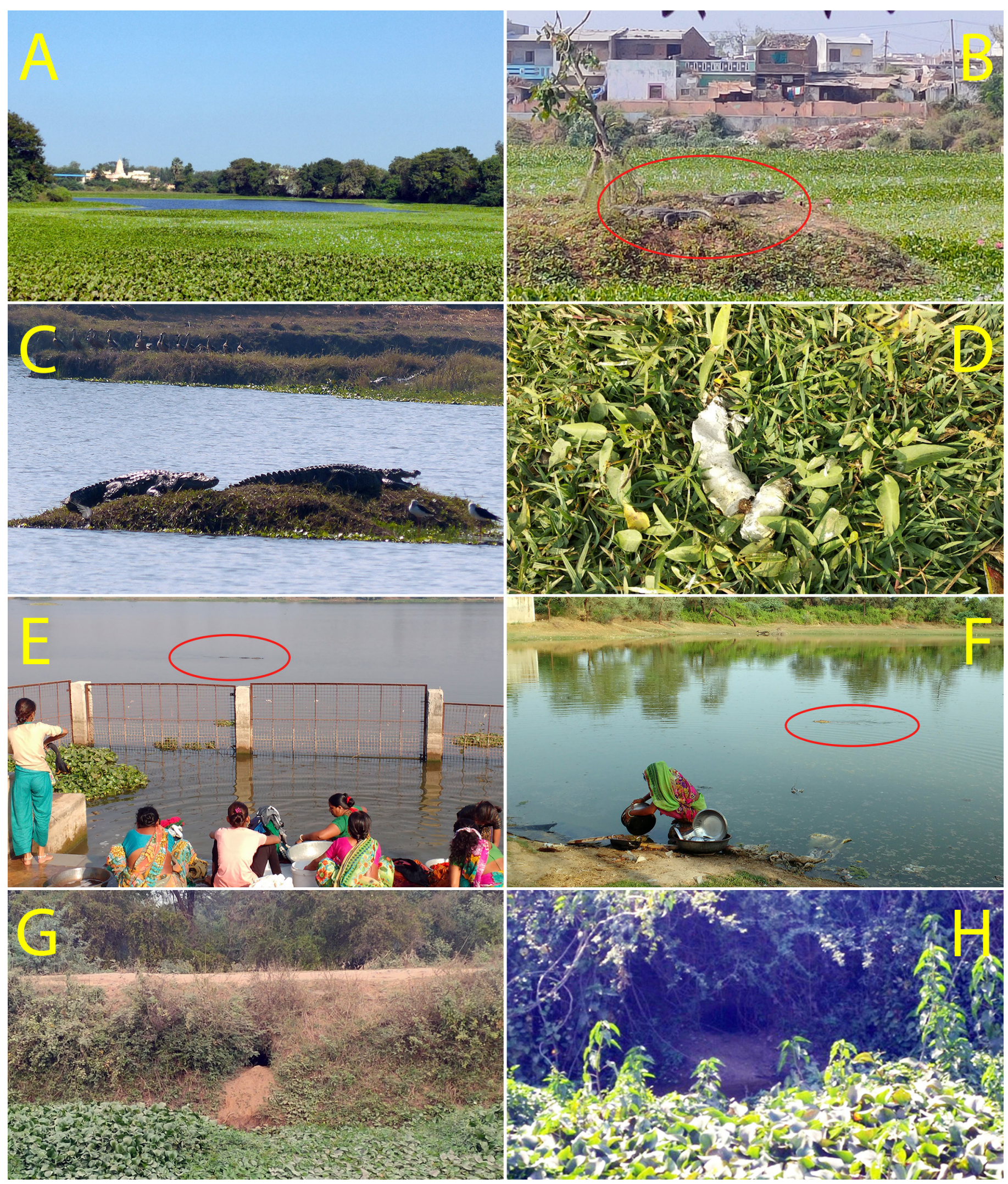

Fig. 2. The pond in Dabhou inundated with Water Hyacinths (Eichhornia crassipes) (A); Marsh Crocodiles (Crocodylus palustris) basking at the pond in Dabhou (B); crocodiles basking on a mound in Heranj (C); crocodile scat on the bank of the pond in Vaso (D); metal framework to prevent humancrocodile conflict in Deva (note the crocodile beyond the barrier) (E); human-crocodile interaction in Petli (F); a crocodile den along a road in Deva (G); crocodile den on the bank of the pond in Deva $(\mathrm{H})$. Photographs by Neel Talati. 
tracking individuals to assess movements between wetlands and determine the carrying capacities of individual ponds.

Three human-crocodile conflicts, two fatal and one non-fatal, have been reported in Anand and Kheda Districts (Vasava et al. 2015a; Vasava 2016b; Rupera 2019), the National Chambal Sanctuary (Rao and Guriwar 2013), and elsewhere (e.g., Whitaker 2007). Rural communities such as those where we conducted surveys share space with crocodiles, and interactions are inevitable (Fig. 2). To mitigate human-crocodiles conflicts, enhance awareness, and promote conservation efforts, the crocodile counts sponsored by the Volunteer Nature Conservancy's Vidyanagar Nature Club (https://vncindia.org/) (Vasava et al. 2015a, 2015b; Vasava 2016a, 2017, 2018, 2019, 2020, 2021) use a multi-approach strategy that includes "identifying conflict hotspots, modeling mugger habitat suitability and preparing conflict risk maps, understanding attitudes of the local people, providing training to the personnel's [sic] involved in conflict mitigation and preparing a guideline for monitoring and conflict mitigation" in order to resolve "the conflict to a great extent" (https:// vncindia.org/projects/human-crocodile-conflicts/). We laud their efforts.

\section{Acknowledgement}

We thank SHODH (Scheme-Developing-High-QualityResearch), Education Department, Government of Gujarat, for financial support.

\section{Literature Cited}

Downs, C.T., C. Greaver, and R. Taylor. 2008. Body temperature and basking behaviour of Nile crocodiles (Crocodylus niloticus) during winter. Journal of Thermal Biology 33: 185-192. https://doi.org/10.1016/j.jtherbio.2008.02.001.

Fukuda, Y., K. Saalfeld, G. Webb, C. Manolis, and R. Risk. 2013. Standardised method of spotlight surveys for crocodiles in the tidal rivers of the Northern Territory, Australia. Northern Territory Naturalist 24: 14-32.

Menzies, R.A., J.A. Kushlan, S. Journal, and N. Sep. 2014. Genetic variation in populations of the American Crocodile. Journal of Herpetology 25: 357-361. https://doi.org/10.2307/1564598.
Ministry of Environment and Forests. 2011. National Wetland Atlas. Ministry of Environment and Forests, Government of India, Space Applications Centre (ISRO), Ahmedabad, India.

Prasad, S.N., T.V. Ramachandra, N. Ahalya, T. Sengupta, A. Kumar, A.K. Tiwari, V.S. Vijayan, and L. Vijayan. 2002. Conservation of wetlands of India - a review. Tropical Ecology 43: 173-186.

Rao, R.J. and R.K. Gurjwar. 2013. Crocodile human conflict in National Chambal Sanctuary, India, pp. 105-109. In: A. de Silva (compiler), World Crocodile Conference. Proceedings of the 22nd Working Meeting of the IUCN-SSC Crocodile Specialist Group. May 21-23 2013. Negombo, Sri Lanka. IUCN, Gland, Switzerland.

Rupera, P. 2019. 12-foot-long crocodile caged after scary encounter in Traj lake. The Times of India (Vadodara), 7 July 2019. <https://timesofindia.indiatimes. $\mathrm{com} / \mathrm{city} /$ vadodara/12-foot-long-croc-caged-after-scary-encounter-in-trajlake/articleshow/70110228.cms>.

Vasava, A. 2016a. Charotar Crocodile Count - 2016. 16-17th January 2016. Voluntary Nature Conservancy, Gujarat, India. https://doi.org/10.13140/ RG.2.1.1970.3449.

Vasava, A. 2016b. Charotar's Crocodiles. Sanctuary Asia 36(2): 36-41.

Vasava, A. 2017. 4th Charotar Crocodile Count - Counting Crocodile for Conservation. 7th-8th January 2017. Voluntary Nature Conservancy, Gujarat, India. https://doi.org/10.13140/RG.2.210821.04325.

Vasava, A. 2018. 5th Charotar Crocodile Count - 2018. Counting Crocodile for Conservation. 6th-7th January 2018. Voluntary Nature Conservancy, Gujarat, India.

Vasava, A. 2019. 6th Charotar Crocodile Count - 2019. Counting Crocodile for Conservation. 4th-6th January 2019. Voluntary Nature Conservancy, Gujarat, India.

Vasava, A. 2020. 7th Charotar Crocodile Count - 2020. Counting Crocodile for Conservation. 3rd-5th January 2020. Voluntary Nature Conservancy, Gujarat, India.

Vasava, A. 2021. 8th Charotar Crocodile Count-2021. Counting Crocodile for Conservation. 9-10 January 2021. Voluntary Nature Conservancy, Gujarat, India.

Vasava, A., D. Patel, R. Vyas, V. Mistry, and M. Patel. 2015a. Crocs of Charotar: Status, Distribution and Conservation of Mugger Crocodiles in Charotar Region, Gujarat, India. Voluntary Nature Conservancy, Vallabh Vidyanagar, India.

Vasava, A., R. Vyas, and D. Patel. 2015b. Counting Mugger Crocodiles in Charotar 2015. Voluntary Nature Conservancy, Vallabh Vidyanagar, India.

Vyas, R. 2010. Mugger (Crocodylus palustris) population in and around Vadodara city, Gujarat state, India. Russian Journal of Herpetology 17: 43-50.

Vyas, R. 2012. Current status of Marsh Crocodiles Crocodylus palustris (Reptilia: Crocodylidae) in Vishwamitri River, Vadodara City, Gujarat, India. Journal of Threatened Taxa 4: 3333-3341. https://doi.org/10.11609/JoTT. o2977.3333-41.

Whitaker, N. 2007. Survey of Human/Crocodile Conflict in India, Maharashtra State, December 2007. Madras Crocodile Trust, Madras, Tamil Nadu, India

Whitaker, R. and Z. Whitaker. 1984. Reproductive biology of the mugger (Crocodylus palustris). Journal of the Bombay Natural History Society 81: 297-317. 